\section{QIJEI}

International

Journal for

Educational Integrity

\title{
Ensuring integrity in educational assessment
}

\author{
Michael Steer and Frances Gentle \\ Renwick Centre, Royal Institute for Deaf and Blind Children, and \\ The University of Newcastle, New South Wales
}

Keywords: blind and vision impaired students, assessment, educational accommodations, integrity

\begin{abstract}
This paper recommnends an approach to educational assessment of students who are blind or vision impaired which takes into account both issues of integrity and educational accommodations that 'level the paying field'. The paper provides a taxonomy of the variety of educational assessment accommodations available for formal and informal tasks in assessing students who are blind or vision impaired. Teachers can enhance educational integrity by ensuring the participation of students in the development of appropriate educational accommodations, and by facilitating the development of students' self-advocacy and problem solving skills.
\end{abstract}

\section{Introduction}

The term educational integrity is, like the Hydra of Greek mythology, a many-headed beast. One of its many heads, or focal areas of fascination for readers of this journal is "academic integrity", mostly having to do with dishonest practice in educational settings, but there are other clusters of interest that are at least as important to educators. The word integrity (with such complex words as "policy" and "right"), has a variety of meanings. For example, the Online Free Dictionary (Farlex, 2005) provides at least three definitions of the term. Integrity can imply the following, according to its context: either (a) steadfast adherence to a strict moral or ethical code, (b) the state of being unimpaired; soundness, or (c) the quality or condition of being whole or undivided; completeness. It is the last of these definitions in relationship to the educational assessment of students who are blind or vision impaired that this paper addresses.

\section{Background}

The authors of this paper coordinate the postgraduate Vision Impairment Program at the Renwick Centre, located at North Rocks in Sydney. Renwick Centre is a locus for research and professional studies in the field of education for children who have sensory disabilities. It is administered by the Royal Institute for Deaf and Blind Children and affiliated with The University of Newcastle. This paper's methodology is partially empirical in nature, based upon author observation supplemented by the inclusion of references from current professional literature. Its content is the product of practitioner observation and its aim is to present the reader with useful information on the various types of accommodation, as well as a number of fundamental principles underpinning policies that intend to 'level the playing field' and maximise the participation of students with vision impairments in the various forms of student assessment that are an important part of school life. It is acknowledged that much of the information presented here is not the product of original experimental research. However, the significance of the paper is that to date, the professional literature on this important topic has seldom if ever, linked disability access issues to those of educational integrity. Neither has it yet provided a taxonomy of universally accepted educational assessment accommodations. It is likely that after having read this article, readers with even a limited background in the education of students with vision

The International Journal for Educational Integrity is available online at:

http://www.ojs.unisa.edu.au/journals/index.php//JEl/

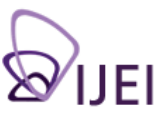


impairments will be in a better position to make recommendations about accommodations. As importantly, the article will also be helpful to those who are asked to comment on rationales for using various types of accommodation. Further, it is likely that disability issues require greater consideration than they have previously received in the general academic arena, so that together (generalist and specialist) we can move toward 'universal design' of curriculum content and away from traditional ideas of using 'special approaches' for students with disabilities, based on a notion that by accommodating them, we are doing them a favour.

\section{Students with vision impairments}

There are currently little (if any) reliable data on the number of students who are blind or vision impaired in Australian schools. Estimates vary greatly by source and method of measurement, as well as by inclusion criteria. For example, an Australian Institute of Health and Welfare survey (AlHW, 1998) indicated that approximately 13,800 children were reported as having health conditions related to cataract and retinal disorder. It is generally held, however, that there are between 2,500 and 3,000 children of school age with low vision who require special educational assistance, and approximately 300 school students Australia-wide who require Braille for purposes of literacy and numeracy acquisition (Steer, 2004). These children, as Foreman (1998, pp. 86-7) has pointed out, are in the majority of cases to be found in regular community school classrooms, being taught largely by generic classroom teachers who are supported by visiting teachers with specialist skills in vision impairment.

Assessment is a highly important component of a student's education that ought to occur regularly, and this is particularly the case for students who are blind or vision impaired. Assessment generally provides the basis for long-term educational decisions. It is important therefore, for teachers, parents, students, family members and caregivers of children with vision impairments to become aware of the assessment process and the several types of accommodation that are used to enable access to the resources and lessons provided to the sighted peers of the student who is vision impaired. Many of us in the field have for years associated the term 'accommodation' with the mechanism through which the focussing apparatus of the eye adjusts to objects at different distances.

However, in the context of educational assessments, the term has quite another meaning. Educational accommodations, as Elliott, Thurlow, Ysseldyke and Erickson (1997), have pointed out, are alterations "in the way that an assessment or a test is administered" (p. 2). They are "provided because of a particular student need" (Elliot et al., 1997, p. 2). These alterations are obviously not made in order to give a student an advantage, but to level the playing field. When students with vision impairments use assessment accommodations, it is so that they can show what they know, without being impeded by their disabilities. As an example, imagine Bruce (a high-schooler) who has Leber's Amaurosis, a degenerative condition that leads to loss of central vision, who is working towards the same instructional goals or standards as other students in his classroom. To participate in the assessment, he needs either (a) an electronic Braille note-taker or perhaps a laptop to write his or her responses, and (b) extended time to complete the test. Via the teacher providing these response and timing accommodations, Bruce (and other students with significant disabilities), who would previously have been excluded from classroom assessments, are afforded the means to participate with their non-disabled peers.

\section{Educational accommodations}

Accommodations are not implemented to give students with disabilities an advantage over other students, but instead are provided to give students the chance to participate in and benefit from the educational environment. This is where the concept of 'Equivalent versus Equal Treatment' is important. Treating all students in the same way is considered discriminatory in some jurisdictions, since disabilities take away the opportunity for students with disabilities to learn or demonstrate what they have 
learned (American Foundation for the Blind, 2006). The accommodation becomes the 'equalizer' and the vehicle through which integrity in the educational process is assured. Students with disabilities should still be required to demonstrate their ability to meet the essential requirements of a class, without compromising the educational integrity or lowering the academic standards of the class.

Educational accommodation policies between schools vary tremendously and it is not uncommon in the American and British literature to learn that an accommodation permitted in one school system is prohibited in another. Part of the reason for this variability is perhaps due to the lack of a good research base for identifying appropriate accommodations. Current literature indicates that there is nowhere a set of universally approved educational assessment accommodations (National Center on Educational Outcomes, 2006). However, several authors agree that accommodations can be organised into a number of categories (American Foundation for the Blind, 2006; American Printing House, 2005). It is the purpose of this paper to focus and elaborate upon these.

\section{Decisions}

Decisions about assessment accommodations should at best be based on an estimate by a Vision Support Teacher, as part of an Individualised Educational Program (IEP) team, of what a particular student needs in order to be provided with an equal opportunity to show what s/he knows without the impediment of a vision impairment. As noted by Heubner, Merk-Adam, Stryker and Wolffe (2004), decisions regarding assessment accommodations should be orchestrated by "someone with a high level of expertise in the effects of vision impairment on learning" (p. 12).

Decisions regarding assessment accommodations made by the IEP team should be made in collaboration with the student and his/her family, with sensitivity to the individual strengths and needs of the student (SPEVI, 2004).

It is important that accommodations do not compromise what the test or assessment is purporting to measure. This underscores the importance of making sure that the educational decision-makers know the purpose of an assessment and the skills or constructs it is trying to measure. These factors, together with the student's needs, determine the appropriateness of specific assessment accommodations. As Elliott et al. (1997) have pointed out,

the IEP team will also have to make decisions about the kinds of accommodation a student needs. For example, should a student be permitted to use a talking calculator during an assessment? Should the student memorise the formulas to solve problems, or should these be provided? If a test is measuring the use of formulas to solve problems, then the team may decide that allowing a student to use a calculator, if one is needed, is appropriate... (p.3)

If this same test is also an attempt at measuring a student's ability to apply formulae in order to derive answers, the IEP team might decide that supplying the formulae would also be appropriate. If however, the test is an attempt at measuring a student's ability to recall formulae and apply them to calculate correct answers through a step-by-step process, then the team might decide that neither of these support mechanisms would be appropriate. Edgemon, Jablonski and Lloyd (2006), have provided a useful summary of research related to the use and usefulness of five major categories of accommodation.

\section{Categories of assessment accommodation}

Although assessing and testing students with vision impairment requires consideration of many types of accommodation, these generally fall into the following five broad categories. Accommodations that are: (1) presentation-related, (2) time- 
related, (3) setting-related, (4) response-related, and (5) aids-related (Jablonski, Edgemon, Wiley \& Lloyd, 2005).

Because of the complex nature of accommodation provision, some of the examples in the following sections overlap and can apply to more than one category. Each of these five broad categories of educational accommodation is presented and discussed.

\section{Presentation-related accommodations}

These allow students to access test directions or content in ways that do not require them to visually read standard print. Alternative modes of access include one or a combination of visual, tactile, and auditory options (University of Kansas, 2005). Table 1 presents examples of some of the sorts of accommodations in this category, several derived from a variety of sources including the authors' own experience, and several adapted from research by Elliott et al. (1997), and Gentle and Wegener (2003).

Table 1. Examples of typical presentation-related accommodations

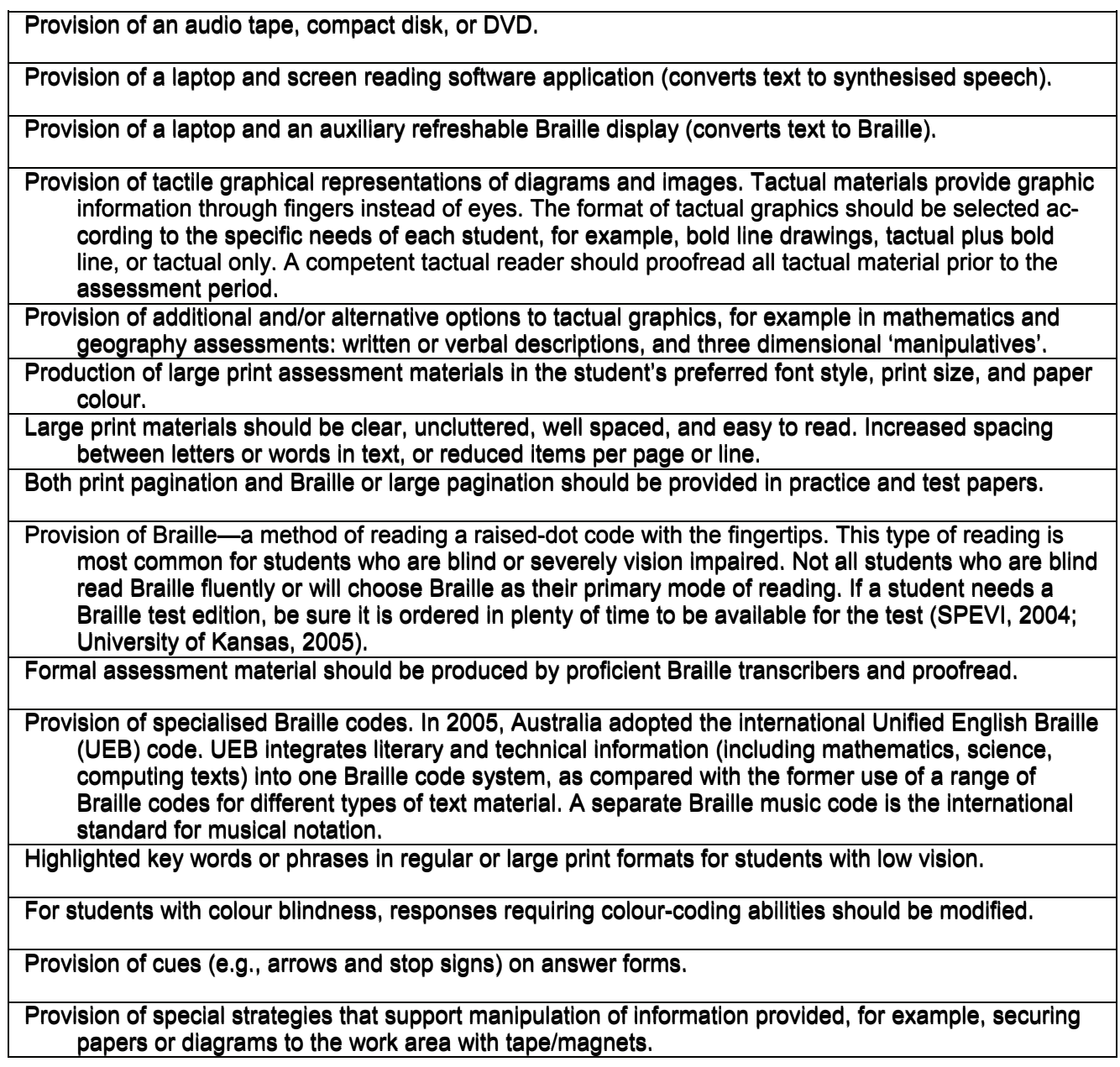

\section{Time-related accommodations}

This type of accommodation extends the time allowed for tests that are time-limited, or permits those giving a test to break its administration into several sections (Edgemon et al., 2006). Additional time may be allowed to reduce visual fatigue for students with low vision, or to allow the additional time required to read and respond in Braille. Table 2 presents examples, derived from the authors' own research and experience, as well as from research by Elliott et al. (1997), and Gentle and Wegener (2003), of some of the types of assessment accommodations in this category: 
Table 2. Examples of typical time-related assessment accommodations



\section{Setting-Related Accommodations}

These sorts of accommodation permit smaller or individual test administration and other types of environmental modifications; for example, special lighting, or the presence during the assessment of a familiar teacher (Edgemon et al., 2006). Table 3 presents examples of some of the types of accommodations in this category:

\section{Table 3. Examples of typical setting-related accommodations}

Administering the test in a small group, study carrel, or individually.

Providing special or modified lighting; for example, to reduce glare.

Providing adaptive or special furniture.

Providing special acoustics as necessary.

Administering the test in a location with minimal distractions (Elliott et al., 1997).

\section{Response-related accommodations}

These sorts of assessment accommodations impact upon the way the student accesses questions and stimulus materials and records answers (Edgemon et al., 2006; Gentle \& Wegener, 2003). For example, a student might dictate an answer to a scribe/notetaker, use a word processor fitted with screen reading software such as JAWS or WindowEyes, use a Perkins or Mountbatten Brailler, or record answers in large print in a specially prepared test booklet. Table 4 presents examples of some of the types of accommodations in this category:

Table 4. Examples of typical response-related accommodations

\begin{tabular}{|l|}
\hline Providing separate booklets for questions and stimulus materials in Braille or large print. \\
\hline Allowing marking of answers in the booklet. \\
\hline Tape recording responses for later verbatim translation. \\
\hline Allowing use of a scribe/notetaker. \\
\hline Providing copying assistance between drafts. \\
\hline Adapting or modifying content of questions requiring vision to answer correctly. \\
\hline $\begin{array}{l}\text { Using transcriber's notes to explain unfamiliar concepts; for example, mathematics or science symbols } \\
\text { and terms. }\end{array}$ \\
\hline $\begin{array}{c}\text { Selecting alternative assessment methods; for example, oral presentation instead of a written paper } \\
\text { (Elliott et al., 1997; Gentle \& Wegener, 2003). }\end{array}$ \\
\hline
\end{tabular}

\section{Aids-related accommodations}

These types of accommodation involve the use of devices during the assessment and consequently, some of the examples in the category overlap or are duplicated by 
examples in the other categories. Table 5 presents a selection of the sorts of accommodations in this category.

Table 5. Examples of typical aids-related accommodations

\begin{tabular}{|c|}
\hline $\begin{array}{l}\text { gnification Devices: Some students with vision impairments read regular print materials and enlarge } \\
\text { the print by using magnification devices. These include free standing or handheld magnifiers, } \\
\text { enlarged computer monitors, or computers with screen enlargement software programs. Some } \\
\text { students also use a Closed Circuit Television (CCTV) to enlarge print and display printed material } \\
\text { with various image enhancements on a screen (University of Kansas, 2005). }\end{array}$ \\
\hline $\begin{array}{l}\text { Large Print (LP): LP editions of tests are required for some students with vision impairments. A regular } \\
\text { print test can be enlarged through photocopying, or an electronic version of a test can be manipu- } \\
\text { lated to reformat test items and enlarge or change the font as needed. All text and graphic materi- } \\
\text { als, including labels and captions on pictures, diagrams, maps, charts, exponential numbers, } \\
\text { notes and footnotes, must be presented in at least 18-point type for students who need large print. } \\
\text { If a student needs a large print test edition, the test administrator must be sure it is ordered in } \\
\text { plenty of time to be available for the test. }\end{array}$ \\
\hline $\begin{array}{l}\text { Equipment for Highlighting and Labelling Information: It may be necessary, for example, to secure or } \\
\text { have available equipment such as tactile rulers, paper clips, blue tack, sticky notes, removable } \\
\text { markers for multiple-choice questions, and highlighting pens. }\end{array}$ \\
\hline $\begin{array}{l}\text { Subject-Specific Materials: Each course or subject may need unique equipment. Mathematics or sci- } \\
\text { ence courses may need a graphics or talking calculator. Language Arts or Social Science courses } \\
\text { may need an electronic dictionary. }\end{array}$ \\
\hline commodation that a student needs that does not fit under the four categories \\
\hline
\end{tabular}

\section{When to use educational accommodations}

Accommodations should be provided for the assessment, as Elliot et al. (1997) have pointed out, when they are routinely provided during classroom instruction. In other words, when classroom accommodations are made so that learning is not impeded by a student's disability, those accommodations should generally be provided during the assessment. Perhaps the most controversial accommodation decisions involve reading tests to students and recording student responses. When a reading test is measuring reading decoding ability, providing a reader compromises what the test is measuring. However, if the purpose of the test is to measure ability to gain understanding or to interpret written language, the use of a reader would be appropriate. Similarly, if a student with a vision impairment is unable to record complete thoughts in writing due to his/her disability, but is able to verbally express thoughts well, then a tape recorder could be used and later transcribed for scoring purposes, or a scribe/notetaker might be provided at the time of the test. Not all parts of a test, even within a single content area, necessarily measure the same skill, so that it becomes important to know (a) the purpose of the test and its parts, (b) what is to be measured, and (c) what accommodation would be appropriate. No accommodation should be provided to the student for the first time on the day of the test or to provide an unfair advantage.

\section{Special provisions}

A major concern for Vision Support Teachers supporting senior students has to do with where and how to make the application to Government for special provisions (Heumann \& Hehir, 1995). These result from Education Department policies that allow eligible students to demonstrate their knowledge and capability in a variety of different ways. As examples of this type of State Government requirement, Nagel (2003) has reviewed modifications to the Victorian Curriculum and Assessment Authority's (VCAA) special provisions that affect administration of the Victorian Certificate of Education (VCE, Year 12 level).

\section{Fundamental principles}

There are, according to current literature on the topic, several common principles, presented in Table 6, that underlie those accommodation policies that intend to maximise the participation of students with vision impairments (Koenig \& Holbrook, 2000; Kelly \& Gale, 1998; Georgia Department of Education, 2002). 
Decisions about instructional accommodations must be made with the student's needs in mind: The key question to ask is, "How are these accommodations direetly linked to the student's learning needs?" (Koenig \& Holbrook, 2000, p: 177):

Use a simple form Indleating factors to consider when making accommodetion declsions, and docu= ment the need for the accommodations: The form will help IE $\mathrm{P}$ decision=makers consider the most relevant variables (e:g:, the ways in which the student's disability is likely to interfere with perform = ance) rather than ifrelevant considerations (e:g: which program of study the student is in, how well the student is likely to perform): The form used to make decisiens should be attached to the student's IEE to provide offieial documentation (Kelly \& Gale, 1998; Georgia Department of Edu= cation, 2002):

Afrange that the people who know the student make the decisions about accommodations: Typically these will be teachers, parents or guardians, of IEF team members: In addition to being part of the decision process, parents must be made aware of the need for assessment accommodations and any Implet of their use in their chlld's testing program (Kelly \& Gele, 1998).

Ensure congruence between what happens during classfoom instruction, classroom testing, end school system or state assessments: The first time a student receives an accommodation should hot be on the day of a test or assessment: There should be a natural flow between what occurs during classroom instruction and what is occurring during assessment: In some cases, accommodations provided during instruetion may not be appropriate for a classroom test or for a state assessment situation: For example, providing guided practice and prompts to assist a student in deriving an answer may be appropriate for instruction but not during essessments (1⿴囗⿱一一) 2006; Georgla Department of Educatlon, 2003).

Consider the type of test: Some Australian states use norm=referenced tests (NRT) and some use erite= rion=referenced tests (CRT): Other states use both. Norm=referenced tests allow comparisens to norms developed under stenderdised procedures; criterion=referenced tests essess whether or not students can do particular tasks, but do not compare a student's performance with the perform= ance of a standardisation group. While CRFs allow greater flexibility in providing accommodations, NRTs allow their use as well (Kelly Gale, 1998):

Classroom teachers, specialist Vision Support Teachers, parents/caregivers, and the IEP team together have an important role in developing independence and selfadvocacy skills in students with vision impairments. Wolffe (2006) described selfadvocacy as the ability to describe one's ability in functional terms, including accommodation needs. Wolffe asserted that children with disabilities, including those with vision impairments, will not develop coping, strategising, and problem solving skills if well-meaning parents, teachers, peers and others do the problem solving for them.

\section{Conclusion}

This paper has attempted to blend the need for educational integrity in the educational assessment of students who are blind or vision impairment with an array of educational accommodations that 'level the paying field' for those students with their sighted peers, and that enables them to demonstrate what they have learned. It has, perhaps for the first time in the professional literature, provided a taxonomy of the variety of educational assessment accommodations that should be considered when planning formal and informal assessment tasks. Students with vision impairments need to be involved in the development of educational accommodations implemented on their behalf. This includes being involved in any modifications to assessment procedures, timetables, and time provisions. Teachers can enhance educational integrity by facilitating the development of self-advocacy and problem solving skills through explicitly teaching note-taking skills, information prioritising skills, essay planning techniques, summarising skills, review strategies, and methods of identifying main information themes and points. Like their sighted peers, the benefits of educational integrity are attained through enhanced fluency in reading, writing, use of technology and effective assessment strategies. These are all vital constituents of future success.

\section{Authors' biographies}

Dr Mike Steer is Senior Lecturer in Vision Impairment at Renwick College, Royal Institute for Deaf and Blind Children and The University of Newcastle. Past appointments include Director of the NSW Office on Disability, Principal Advisor, Disability Policy, Community Services Victoria; Director, Integration Unit, Ministry of 
Education (Vic) and Adjunct Professor in the Faculty of Health \& Behavioural Sciences, Deakin University, Director of Special Education, Government of Newfoundland and Labrador, Canada, Principal, Psychoeducational Teaching Laboratory, Syracuse University, USA, and Principal, Montreal Association School for the Blind.

Frances Gentle is a Lecturer in Vision Impairment at the Renwick College, Royal Institute for Deaf and Blind Children NSW, affiliated with the University of Newcastle. She has worked in the fields of general special education and vision impairment for over 25 years. Past appointments have included Vision Services Coordinator, St Edmund's School for Students with Vision Impairment and Other Special Needs, Sydney; Special Educator, Lucas Gardens School, Sydney; Special Educator, Tokyo International Learning Centre, and Tokyo Vocational Development Centre for the Blind, Japan. Professional activities include Pacific Chairperson, the International Council for the Education of People with Visual Impairment (ICEVI); Vice-Chair, Australian Braille Authority (ABA); Member of the Editorial Committee, Journal of South Pacific Educators in Vision Impairment (JSPEVI); and Member of the Examinations Board, Australian Braille Authority.

\section{References}

AlHW. (1998). Children with disabilities in Australia. Canberra: Australian Institute for Health and Welfare.

American Foundation for the Blind. (2006). Disability rights resources for people who are blind or visually impaired. Retrieved 18 September 2006 from www.afb.org/ section. asp? documentid $=524$

American Printing House. (2005). Accommodations in the test-taking environment. Retrieved 18 September, 2006 from http://www.aph.org/ advisory/2005adv12.html

Ball State University. (2006). Resources, tips, and suggested accommodations for students who are blind or visually impaired. Retrieved 18 September 2006 from www.bsu.edu/dsd/article/0,14806,00.html

Edgemon, E. A., Jablonski, B. R., \& Lloyd, J. W. (2006). Large-scale assessments: A teacher's guide to making decisions about accommodations. Teaching Exceptional Children, 38(3), 6-11.

Elliott, J., Thurlow, M., Ysseldyke, J., \& Erickson, R. (1997). Providing assessment accommodations for students with disabilities in state and district assessments (Policy Directions No. 7). Minneapolis, MN: University of Minnesota, National Center on Educational Outcomes. Retrieved 21 March 2006, from: http:// education.umn.edu/NCEO/OnlinePubs/Policy7.html

Farlex. (2005). Online Free Dictionary. Retrieved 21 September 2006 from http:// www.thefreedictionary.com/integrity

Foreman, P. (1998). Integration and inclusion in action. Sydney: Harcourt Brace.

Gentle, F. \& Wegener, E. (2003). Exam preparation for students with vision impairments. Paper presented at the SPEVI Conference, Queensland, January 2003.

Georgia Department of Education. (2002). Accommodations for students with visual impairments. Retrieved 18 September 2006 from www.glc.k12.ga.us/passwd/ trc/ttools/attach/accomm/visimp.pdf

Huebner, K. M., Merk-Adam, B., Stryker, D., \& Wolffe, K. (2004). The national agenda for the education of children and youths with visual impairments, including those with multiple disabilities (Revised). New York: AFB Press.

Heumann, J.E. \& Hehir, T. (1995). Policy guidance on educating blind and visually impaired 
Jablonski, B., Edgemon, E. A., Wiley, A. W., \& Lloyd, J. W. (2005). Large-scale testing accommodations for students with disabilities. Manuscript submitted for publication.

Kelly, P., \& Gale, G. M. (1998). Towards excellence: Effective education for students with vision impairments. NSW: North Rocks Press.

Koenig, A. J., \& Holbrook, C. (Eds.). (2000). Foundations of education for the visually impaired. New York: American Foundation for the Blind.

Nagel, L. (2003). VCAA changes to special provision. SVRC Bulletin, 11. Retrieved 24 March 2006 from http://www.svrc.vic.edu.au/11'03.html

National Center on Educational Outcomes. (2006). Online accommodation studies. Retrieved 18 September 2006 from www.education.umn.edu/NCEO/ AccomStudies.htm

SPEVI (South Pacific Educators in Vision Impairment). (2004). Principles and standards for the education of children and youth with vision impairments, including those with multiple disabilities. NSW: SPEVI.

Steer, M. (2004). Low vision technology 2020: What does the future hold? Paper presented at the National Conference of the Round Table on Information Access for People with a Print Disability, Sydney, May 2004.

University of Kansas. (2005). Presentation assessment accommodations. Retrieved 23 March 2006 from: http://www.specialconnections.ku.edu/cgi-bin/cgiwrap/ specconn/main.php?cat=assessment\&subsection=testaccomm/presentation

Wolffe, K. (2006). Making it! Transition competencies for youth with visual disabilities. Presentation to SPEVI NSW Chapter Dinner Meeting, Royal Institute for Deaf and Blind Children, North Rocks, September 2006. 